\title{
GESTÃO DE COMPETÊNCIAS E GESTÃO DE DESEMPENHO: tecnologias distintas ou instrumentos de um mesmo construto?
}

\author{
Hugo Pena Brandão \\ Mestre em Administração pela Universidade de Brasília (UnB). \\ E-mail: hugopb@tba.com.br \\ Tomás de Aquino Guimarães \\ Mestre em Administração pela FGV/EAESP, Doutor em Sociologia pela USP, Professor Adjunto e \\ Coordenador do Curso de Mestrado em Administração da Universidade de Brasília (UnB). \\ E-mail: tomas@unb.br
}

\begin{abstract}
RESUMO
Este artigo discute até que ponto a gestão de competências e a gestão de desempenho constituem tecnologias gerenciais distintas ou partes interdependentes de um mesmo construto. Os autores apresentam uma revisão da literatura sobre os conceitos que permeiam esses modelos de gestão, suas características e aplicações no campo organizacional e analisam as principais semelhanças e diferenças entre eles, sendo possível concluir que, mais que tecnologias independentes, a gestão de competências e a gestão de desempenho parecem complementar-se em um contexto mais amplo de gestão organizacional. Ao final, é proposta uma nova abordagem conceitual que procura considerar a relação de interdependência entre esses modelos de gestão.
\end{abstract}

\section{ABSTRACT}

This article discusses in what sense competence-based management and performance-based management are independent managerial technologies or parts of the same construct. The authors present a literature review upon the concepts of these management methodologies, their characteristics and applications in the organizational field, and analyze the main similarities and differences between them. It is possible to conclude that, more than independent technologies, competencebased and performance-based management methodologies appear to be complementary and part of a wider organization management model. A new conceptual approach, leading to emphasize the interdependence relationship between these management methodologies, is proposed.

\section{PALAVRAS-CHAVE}

Competência, gestão de competências, gestão de desempenho, gestão estratégica de recursos humanos, tecnologias de gestão.

\author{
KEY WORDS
}

Competence, competence-based management, performance-based management, strategic human resource management, managerial technologies. 


\section{INTRODUÇÃO}

A sociedade contemporânea está passando por um período de grandes transformações sociais, econômicas, políticas e culturais, que resultam num processo de reestruturação produtiva. Nas organizações, o impacto dessa reestruturação materializa-se por intermédio de processos de racionalização organizacional e técnicas que incorporam ao ambiente empresarial novas tecnologias e novos modelos de gestão. Configura-se como desafio às organizações desenvolver e utilizar instrumentos de gestão que lhes garantam um certo nível de competitividade atual e futuro.

As propostas para a obtenção de vantagem competitiva, apesar das diferenças de ordem semântica, parecem caminhar em uma mesma direção: gestão estratégica de recursos humanos (Taylor, Beechler e Napier, 1996); gestão de competências (Prahalad e Hamel, 1990; Heene e Sanchez, 1997); acumulação do saber (Arrègle, 1995; Wright, Van e Bouty, 1995) e gestão do capital intelectual (Stewart, 1998). Percebe-se, nessas proposições, a ênfase nas pessoas como recurso determinante do sucesso organizacional, uma vez que a busca pela competitividade impõe às empresas a necessidade de contar com profissionais altamente capacitados, aptos a fazer frente às ameaças e oportunidades do mercado.

Nesse contexto, é possível visualizar a gestão de competências e a gestão de desempenho como instrumentos que fazem parte de um mesmo movimento, voltado a oferecer alternativas eficientes de gestão às organizações. Mas até que ponto esses instrumentos representam tecnologias de gestão díspares? Não seriam terminologias diferentes utilizadas para representar um mesmo construto? São tecnologias apresentadas como distintas apenas em decorrência de mais um modismo da teoria organizacional?

Busca-se, neste artigo, discutir a evolução, as características e as aplicações práticas da gestão de competências e da gestão de desempenho, bem como identificar as principais semelhanças e diferenças entre essas tecnologias, procurando respostas para as questões acima. Pretende-se, dessa forma, contribuir para o debate teórico e prático em torno do tema e apresentar sugestões de releitura de conceitos.

\section{GESTÃO DE COMPETÊNCIAS: PRINCIPAIS CARACTERÍSTICAS E APLICAÇÕES}

No fim da Idade Média, a expressão competência era associada essencialmente à linguagem jurídica. Dizia respeito à faculdade, atribuída a alguém ou a alguma instituição, de apreciar e julgar certas questões. Por extensão, o conceito de competência veio a desig- nar o reconhecimento social sobre a capacidade de alguém de pronunciar-se em relação a determinado assunto e, mais tarde, passou a ser utilizado, de forma mais genérica, para qualificar o indivíduo capaz de realizar determinado trabalho (Isambert-Jamati, 1997).

A preocupação das organizações em contar com indivíduos capacitados para o desempenho eficiente de determinada função não é recente. Taylor (1970) já alertava, no início do século passado, para a necessidade de as empresas contarem com "homens eficientes", ressaltando que a procura pelos competentes excedia a oferta. Na época, com base no princípio taylorista de seleção e treinamento do trabalhador, as empresas procuravam aperfeiçoar em seus empregados as habilidades necessárias para o exercício de atividades específicas, restringindo-se às questões técnicas relacionadas ao trabalho e às especificações de cargo. Posteriormente, em decorrência de pressões sociais e do aumento da complexidade das relações de trabalho, as organizações passaram a considerar, no processo de desenvolvimento profissional de seus empregados, não somente questões técnicas mas também aspectos sociais e comportamentais relacionados ao trabalho.

Ao definir competência, Zarifian (1996), por exemplo, faz alusão à metacognição e a atitudes relacionadas ao trabalho, baseando-se na premissa de que, em um ambiente dinâmico e competitivo, não é possível considerar o trabalho como um conjunto de tarefas ou atividades predefinidas e estáticas. Para esse autor, competência significa "assumir responsabilidades frente a situações de trabalho complexas [aliado] (...) ao exercício sistemático de uma reflexividade no trabalho" (Zarifian, 1996, p. 5), permitindo ao profissional lidar com eventos inéditos, surpreendentes e de natureza singular.

Sparrow e Bognanno (1994), ao tratar do mesmo tema, fazem referência a um repertório de atitudes que possibilitam ao profissional adaptar-se rapidamente a um ambiente cada vez menos estável e ter uma orientação para a inovação e a aprendizagem permanentes. Segundo esses autores, competências representam atitudes identificadas como relevantes para a obtenção de alto desempenho em um trabalho específico ao longo de uma carreira profissional ou no contexto de uma estratégia corporativa.

Existem, ainda, autores que definem competência não apenas como um conjunto de qualificações que o indivíduo detém. Para eles, é necessário também colocar em prática o que se sabe, ou seja, mobilizar e aplicar tais qualificações em um contexto específico. Dutra, Hipólito e Silva (1998), por exemplo, conceituam competência como a capacidade de uma pessoa de gerar resultados dentro dos objetivos organizacionais. Para 
Ropé e Tanguy (1997), um dos aspectos essenciais da competência é que esta não pode ser compreendida de forma separada da ação.

Durand (1998), por sua vez, seguindo as chaves do aprendizado individual de Pestalozzi ${ }^{1}$, construiu um conceito de competência baseado em três dimensões conhecimentos, habilidades e atitudes -, englobando não só questões técnicas mas também a cognição e as atitudes relacionadas ao trabalho, como mostra a Figura 1. Nesse caso, competência diz respeito ao conjunto de conhecimentos, habilidades e atitudes necessários à consecução de determinado propósito.

Tais dimensões são interdependentes na medida em que, para a exposição de uma habilidade, se presume que o indivíduo conheça princípios e técnicas específicos. Da mesma forma, a adoção de um comportamento no trabalho exige da pessoa, não raras vezes, a detenção não apenas de conhecimentos mas também de habilidades e atitudes apropriadas. Abordagens como essa parecem possuir aceitação mais ampla tanto no ambiente empresarial como no meio acadêmico, visto que procuram integrar diversos aspectos relacionados ao trabalho.

Além do nível individual, o conceito de competência aplica-se também à equipe de trabalho e à organização como um todo. Zarifian (1996) sustenta que não se deve desconsiderar a dimensão da equipe no processo produtivo e sugere que uma competência pode ser atribuída tanto a um indivíduo quanto a um grupo de trabalho. Durand (2000) chama a atenção para esse aspecto ao afirmar que crenças e valores compartilhados pela equipe de trabalho influenciam sobremaneira a conduta e o desempenho de seus componentes.

Prahalad e Hamel (1990) tratam do conceito no nível organizacional, referindo-se à competência como um conjunto de conhecimentos, habilidades, tecnologias, sistemas físicos e gerenciais inerentes a uma organização. Assim, competências essenciais organizacionais são aquelas que conferem vantagem competitiva, geram valor distintivo percebido pelos clientes e são difíceis de serem imitadas pela concorrência. O design de motores leves da Honda e a capacidade de miniaturização da Sony são exemplos de competência citados pelos autores. É possível, portanto, classificar as competências como humanas - aquelas relacionadas ao indivíduo ou à equipe de trabalho - ou organizacionais - aquelas que dizem respeito à organização como um todo.

A gestão de competências pode ser visualizada como uma tecnologia derivada da Resource-Based Management Theory. Essa teoria argumenta que certos atributos organizacionais (recursos) são condicionantes do sucesso da empresa com relação à concorrência. $\mathrm{O}$ pressuposto é o de que o domínio de recursos raros, valiosos e difíceis de serem imitados confere à organização certa vantagem competitiva (Taylor, Beechler e

Figura 1 - As três dimensões da competência

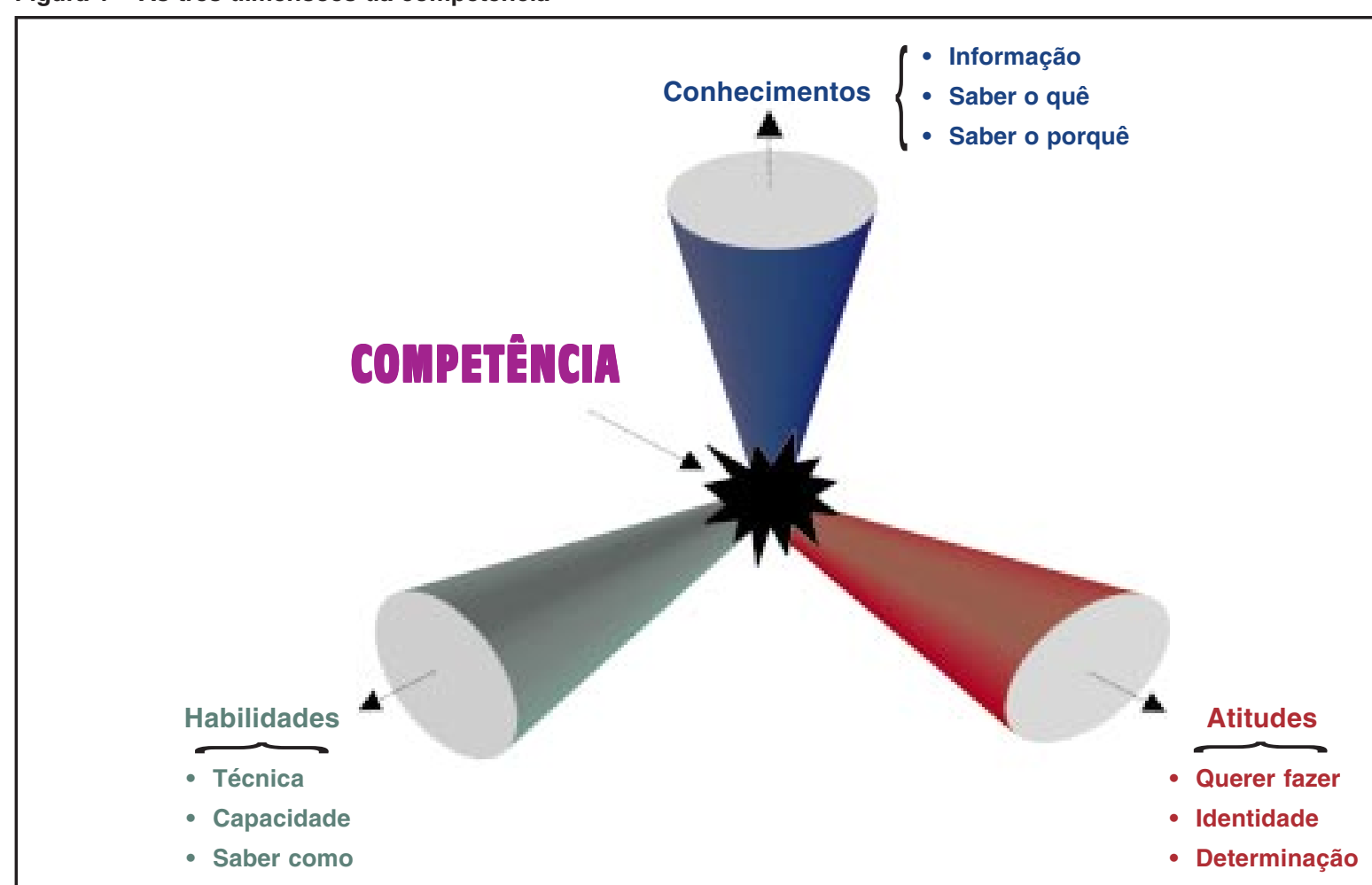

Fonte: Durand (2000) (adaptado). 
Napier, 1996; Barney citado por Raub, 1998). Essa corrente sugere, ainda, que a gestão estratégica de recursos humanos contribui para gerar vantagem competitiva sustentável por promover o desenvolvimento de habilidades, produzir um complexo de relações sociais e gerar conhecimento, ou seja, desenvolver competências.

Diversas empresas têm recorrido à utilização de modelos de gestão de competências, objetivando planejar, selecionar e desenvolver as competências necessárias ao respectivo negócio. Um modelo sugerido por Ienaga (1998) tem como passo inicial a identificação do gap (lacuna) de competências da organização, como mostra a Figura 2. Esse processo consiste em estabelecer os objetivos e as metas a serem alcançados segundo a intenção estratégica da organização e, depois, identificar a lacuna entre as competências necessárias à consecução desses objetivos e as competências internas disponíveis na empresa. Os passos seguintes compreendem o planejamento, a seleção, o desenvolvimento e a avaliação de competências, buscando minimizar a referida lacuna, o que pressupõe a utilização de diversos subsistemas de recursos humanos, entre os quais, recrutamento e seleção, treinamento e gestão de desempenho. A idéia é que a organização e seus profissionais "eliminem as lacunas entre o que podem fazer e o que os clientes esperam que eles façam" (Stewart, 1998, p. 84).

Nesse sentido, a gestão de competências faz parte de um sistema maior de gestão organizacional. Ela toma como referência a estratégia da organização e direciona suas ações de recrutamento e seleção, treinamento, gestão de carreira e formalização de alianças estratégicas, entre outras, para a captação e o desenvolvimento das competências necessárias para atingir seus objetivos. Esse processo pode proporcionar a "consistência interna da estratégia" (Tilles, 1997, p. 6), ou seja, um impacto positivo cumulativo dessas ações sobre o desempenho organizacional.

Seria temerário afirmar que o processo de gestão de competências é do tipo top-down, em que as competências essenciais da organização determinam as competências humanas, ou o contrário, que esse processo seria do tipo bottom-up, em que estas determinam aquelas. A gestão de competências deve ser vista como um processo circular, envolvendo os diversos níveis da organização, desde o corporativo até o individual, passando pelo divisional e o grupal. O importante é que a gestão de competências esteja em perfeita sintonia com a estratégia organizacional (missão, visão de futuro e objetivos). A visão determina o estado futuro desejado pela organização, sua intenção estratégica, e orienta a formulação das políticas e diretrizes e todos os esforços em torno da captação e do desenvolvimento de competências.

\section{GESTÃO DE DESEMPENHO: PRINCIPAIS CARACTERÍSTICAS E APLICAÇÕES}

Embora mecanismos de avaliação de desempenho tenham sido utilizados para o controle dos trabalhadores desde a Antigüidade, foi com o surgimento do capitalismo e das grandes indústrias que a avaliação do

Figura 2 - Identificação do gap de competências

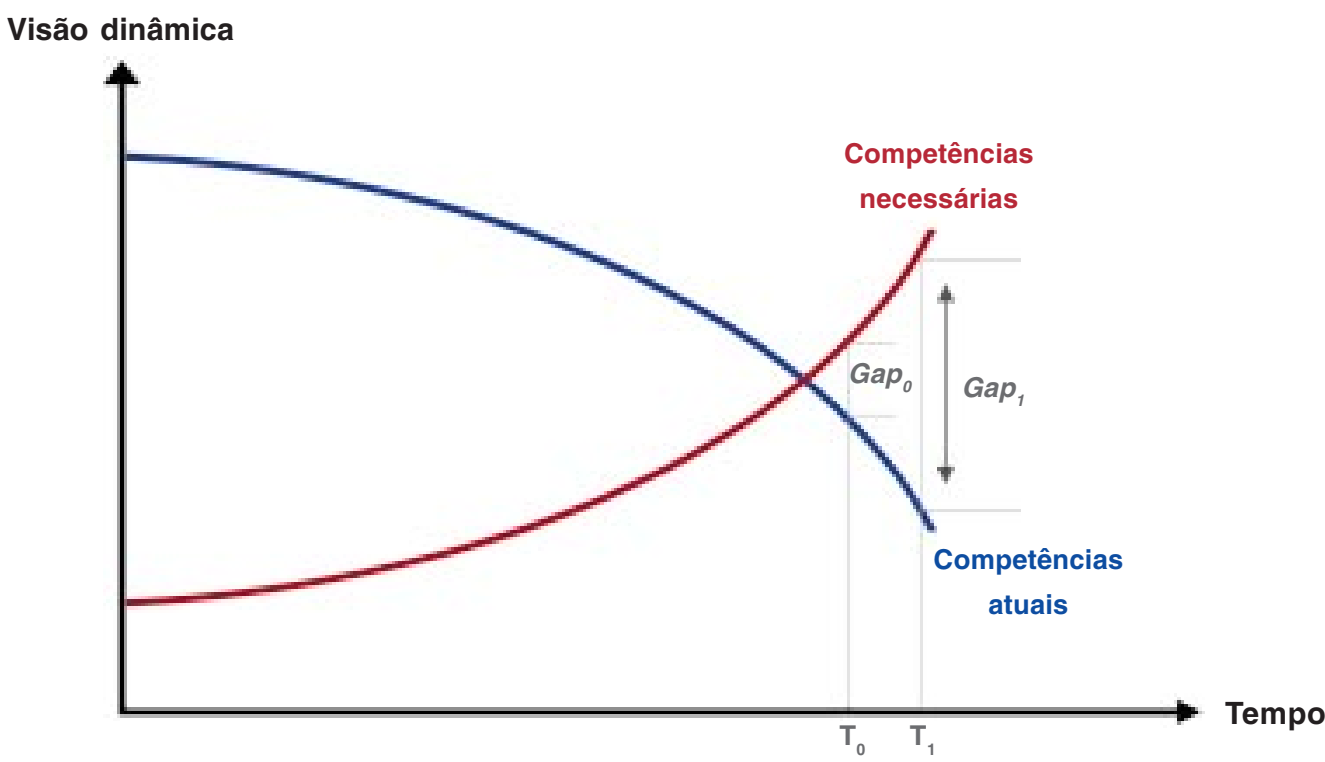

Fonte: lenaga (1998) (adaptado). 
desempenho humano ganhou maior significado. A utilização ampliada de processos e escalas para avaliar o desempenho de empregados tomou corpo com o advento do taylorismo, no início do século passado. As pesquisas de Taylor para a racionalização do trabalho deram origem às primeiras escalas de "avaliação de mérito", aplicadas, na época, para disciplinar o trabalhador e interferir no seu modo de realizar o trabalho.

Ao longo do século XX, a avaliação de desempenho passou das metodologias de controle dos tempos e movimentos para processos que consideram o empregado e seu trabalho como parte de um contexto organizacional e social mais amplo (Guimarães, Nader e Ramagem, 1998). A partir da necessidade das organizações de contar com instrumentos para estimular o trabalhador a adotar ou reforçar determinadas atitudes, as técnicas de avaliação de desempenho foram sendo aperfeiçoadas, valendo-se, principalmente, de contribuições das Ciências Sociais.

No que diz respeito à responsabilidade pela avaliação, por exemplo, essas técnicas evoluíram de um modelo de avaliação de mão única, por meio do qual o chefe realizava unilateralmente um diagnóstico dos pontos fortes e fracos do subordinado, para outros modelos, como a avaliação bilateral, em que chefe e subordinado discutem em conjunto o desempenho deste último, e, mais recentemente, a avaliação $360^{\circ}$, que propõe a utilização de múltiplas fontes, ou seja, a avaliação do empregado por clientes, pares, chefe e subordinados, conforme proposto por Edwards e Ewen (1996).

Assim, diversos têm sido os mecanismos utilizados pelas organizações para a avaliação do desempenho humano no trabalho, cada qual procurando desenvolver metodologias adequadas às suas necessidades e finalidades. Enquanto, na perspectiva funcionalista, a avaliação é vista como um processo que visa ao desenvolvimento de recursos humanos e à melhoria da performance no trabalho (Goodale, 1992; Lucena, 1977), na perspectiva crítica, a avaliação é entendida como um mecanismo utilizado pela organização para exercer o controle psicossocial sobre os trabalhadores (Pagès et al., 1993).

A gestão de desempenho surgiu nos últimos anos como um conceito alternativo às técnicas tradicionalmente utilizadas para a avaliação de desempenho. Avaliar significa, em síntese, comparar os resultados alcançados com os esperados (planejados), de forma que apenas o trabalho previamente planejado deve ser objeto de avaliação. Isso pressupõe não só a comparação entre o que se espera do indivíduo em termos de realização (resultado esperado) e a sua atuação efetiva (trabalho realizado) mas também a existência de algum mecanismo de acompanhamento que permita corrigir desvios para assegurar que a execução corresponda ao que foi planejado (Lucena, 1977; Aluri e Reichel, 1994). O termo gestão dá ao mecanismo de avaliação a conotação de um processo que envolve atividades de planejamento, de acompanhamento e de avaliação propriamente dita (Guimarães, 1998).

As organizações modernas necessitam de mecanismos de avaliação de desempenho em seus diversos níveis, desde o corporativo até o individual, pois, como sugerem Oliveira-Castro, Lima e Veiga (1996), o desempenho no trabalho é resultante não apenas das competências inerentes ao indivíduo mas também das relações interpessoais, do ambiente de trabalho e das características da organização. Um sistema de gestão de desempenho, conforme descrito por Guimarães, Nader e Ramagem (1998), mostra que, no nível corporativo, o planejamento, o acompanhamento e a avaliação restringem-se à missão, à visão e aos objetivos macro, tendo a sustentabilidade da organização como resultado esperado. No nível divisional ou funcional, o interesse recai sobre os objetivos e as metas de cada unidade produtiva da empresa, visando à eficácia organizacional. No nível grupal, a avaliação concentra-se sobre os projetos e processos de trabalho, isto é, sobre as equipes. Finalmente, no nível individual, o objeto a ser avaliado é o resultado do trabalho do indivíduo, do seu comportamento no ambiente de trabalho ou de ambos. Nestes dois últimos níveis, busca-se a qualidade dos produtos e serviços gerados pela organização.

Como visto, a gestão de desempenho faz parte de um processo maior de gestão organizacional, uma vez que permite rever estratégias, objetivos, processos de trabalho e políticas de recursos humanos, entre outros, objetivando a correção de desvios e dando sentido de continuidade e sustentabilidade à organização.

\section{GESTÃO DE COMPETÊNCIAS VERSUS GESTÃO DE DESEMPENHO}

Com base na revisão realizada, é possível indagar até que ponto a gestão de desempenho é algo diferente da gestão de competências. Ambas as tecnologias propõem a necessidade de associar a performance ou as competências da organização com as de seus membros. No caso da gestão de desempenho, por exemplo, alguns autores (Guimarães, 1998; Oliveira-Castro, Lima e Veiga, 1996) sustentam que as organizações deveriam dispor de instrumentos de avaliação de desempenho em seus diversos níveis, do corporativo ao individual. Da mesma forma, na gestão de competências, as proposições de Prahalad e Hamel (1990) e Durand (1998) seguem o mesmo caminho, sugerindo a existência de competências organizacionais e humanas. 
Essas tecnologias de gestão parecem estar baseadas em um mesmo pressuposto: a competência ou o desempenho do indivíduo exercem influência na competência ou desempenho da organização e são influenciados por ela. Enquanto a corrente da gestão de competências argumenta que a competência humana, aliada a outros recursos, dá origem e sustentação à competência organizacional, os autores que defendem a gestão de desempenho alegam que a performance no trabalho é resultante não apenas das competências inerentes ao indivíduo mas também de atributos organizacionais.

A necessidade de associar o desempenho ou as competências humanas com o desempenho ou as competências da organização como um todo faz com que tanto a gestão de desempenho como a de competências estejam inseridas em um contexto de gestão estratégica de recursos humanos, entendida como a função de atrair, desenvolver e manter o pessoal necessário para atingir os objetivos organizacionais, por meio da utilização de sistemas de recursos humanos consistentes entre si e coerentes com a estratégia da organização (Taylor, Beechler e Napier, 1996). Em outras palavras, as duas tecnologias de gestão propõem integrar os subsistemas de recursos humanos - gestão de carreira, remuneração, recrutamento e seleção, treinamento e desenvolvimento, entre outros - e a estratégia organizacional.

Além disso, ambas as tecnologias podem empregar indicadores relacionados tanto ao resultado do trabalho como ao comportamento ou processo utilizado para alcançá-lo. Quando a gestão de desempenho ocorre no nível individual, por exemplo, é possível avaliar o trabalhador tomando como parâmetro não só os resultados decorrentes do trabalho executado mas também a manifestação, por parte do indivíduo, de conhecimentos, habilidades e atitudes que se pressupõe serem relevantes para a consecução dos objetivos organizacionais. Da mesma forma, na gestão de competências, uma competência se traduz tanto pelo resultado alcançado como pelo conjunto de conhecimentos, habilidades e atitudes necessários para atingi-lo. Observam-se, então, até mesmo semelhanças conceituais entre competência e desempenho. O resultado alcançado (desempenho) representa, em última instância, a própria competência do indivíduo.

Outra semelhança é que tanto a gestão de desempenho quanto a de competências presumem um processo que considera a interdependência entre os atos de planejar, acompanhar e avaliar. Sob esse aspecto, nota-se que os processos inerentes às duas tecnologias muitas vezes se sobrepõem, parecendo ser complementares. Na gestão de competências, por exemplo, faz-se necessário contar com algum mecanismo de avaliação de desempenho que permita à empresa identificar seu gap (lacuna) de competências, tanto no nível individual como no organizacional. Inferese, portanto, que a identificação de necessidades de desenvolvimento de competências acontece por meio da gestão de desempenho.

Um outro aspecto que merece ser considerado é a possibilidade de a gestão de desempenho e a de competências contribuírem para o que Pagès et al. (1993) denominaram processos de objetivação e individualização do trabalho e, dessa forma, acabarem constituindo-se em mecanismos de controle social de trabalhadores e de manutenção das estruturas de poder das organizações. Nesse caso, a objetivação refere-se ao processo de traduzir, em termos quantitativos, o desempenho e as competências do indivíduo, buscando estimar o valor de sua contribuição para atingir os objetivos organizacionais. A individualização, por sua vez, nada mais é que o reforço ao individualismo como estratégia para evitar a mobilização de trabalhadores em torno de reivindicações coletivas.

Sob esse ponto de vista, tais tecnologias teriam uso eminentemente patronal e, mais que instrumentos de gestão estratégica de recursos humanos, representariam apenas um exercício convencional de pragmatismo, buscando intensificar o controle social sobre o trabalhador. Segundo Legge (1995), certas práticas de recursos humanos conferem um aspecto de modernidade aos estilos administrativos, mas, na realidade, não negam os princípios fundamentais do taylorismo e do fordismo nem alteram as estruturas de poder nas empresas.

Hirata (1997) e Spink (1997), por sua vez, afirmam que os conceitos de competência, desempenho e empregabilidade $^{2}$ remetem, sem mediações, a um sujeito, à individualização do trabalho e a efeitos excludentes e marginalizadores. Para eles, a possibilidade de concentrar a atenção mais sobre a pessoa que sobre o posto de trabalho e de associar as qualidades requeridas de um indivíduo fortaleceria a divisão da sociedade em um núcleo "altamente capacitado" (ou competente) e uma periferia "desqualificada" e, portanto, excluída do processo produtivo.

Para se configurarem como práticas gerenciais inovadoras, é possível inferir que a gestão de competências e a de desempenho devam ter como objetivo maior não somente a melhoria das performances profissional e organizacional, mas, principalmente, o desenvolvimento das pessoas em um sentido mais amplo. Somente assim a competência e o desempenho representariam, ao mesmo tempo, um valor econômico para a organização e um valor social para o indivíduo. Segundo Zarifian (1999), o desafio é fazer com que a empresa seja não apenas "qualificada", do ponto de vista da competitividade, mas tam- 
bém "qualificante", no sentido de oferecer diversas oportunidades de crescimento a seus membros. Dessa forma, seria possível assegurar certa autonomia às pessoas, como contraponto ao controle social de que falam Legge (1995) e Pagès et al. (1993).

A perspectiva sociológica da abordagem da competência é também explorada por Tanguy (1997), para quem os discursos sobre competência proliferam tanto nas empresas como na esfera educacional. Para ela, "essa noção é invocada tanto pelas políticas de emprego orientadas pela busca da flexibilidade como pelas políticas de mudança da organização do trabalho ou de gestão de pessoal" (Tanguy, 1997, p. 167). Ainda segundo essa autora, ao mesmo tempo em que o domínio de uma profissão, uma vez adquirido, não pode ser questionado, as competências são apresentadas como propriedades instáveis que devem ser sempre submetidas à objetivação e avaliação dentro e fora do ambiente de trabalho.

\section{CONCLUSÕES}

O interesse recente sobre a gestão estratégica de recursos humanos deu origem a uma série de teorias e práticas de recursos humanos, fazendo com que conceitos como o de competência, desempenho e empregabilidade passassem a fazer parte da retórica de muitas organizações, adquirindo diversas conotações e, muitas vezes, sendo utilizados de maneiras distintas tanto no ambiente empresarial como no meio acadêmico. A complexidade do tema tornou a fragmentação teórica inevitável, o que parece natural, pois concepções variadas e até mesmo contraditórias sobre um mesmo assunto talvez sejam a representação mais acurada do mundo pós-moderno.

Embora a gestão de competências e a gestão de desempenho estejam inseridas nesse contexto de fragmentação teórica, é possível perceber a relação de interdependência existente entre elas. Parece necessária a aplicação concomitante dos pressupostos e processos subjacentes a ambos os instrumentos para integrar e direcionar esforços, sobretudo os relacionados à gestão de recursos humanos. Mais que tecnologias independentes ou distintas, a gestão de competências e a de desempenho parecem complementar-se em um contexto mais amplo de gestão organizacional.

Como instrumentos de um mesmo construto, melhor seria cunhar o termo gestão de desempenho baseada nas competências, uma vez que este considera o caráter de complementaridade e interdependência entre competência e desempenho. Parece preciso integrar, em um único modelo de gestão, as atividades de planejamento, acompanhamento e avaliação de desempenho, a partir de um diagnóstico das competências essenciais à organização, desde o nível corporativo até o

Figura 3 - Processo de gestão de desempenho baseada nas competências

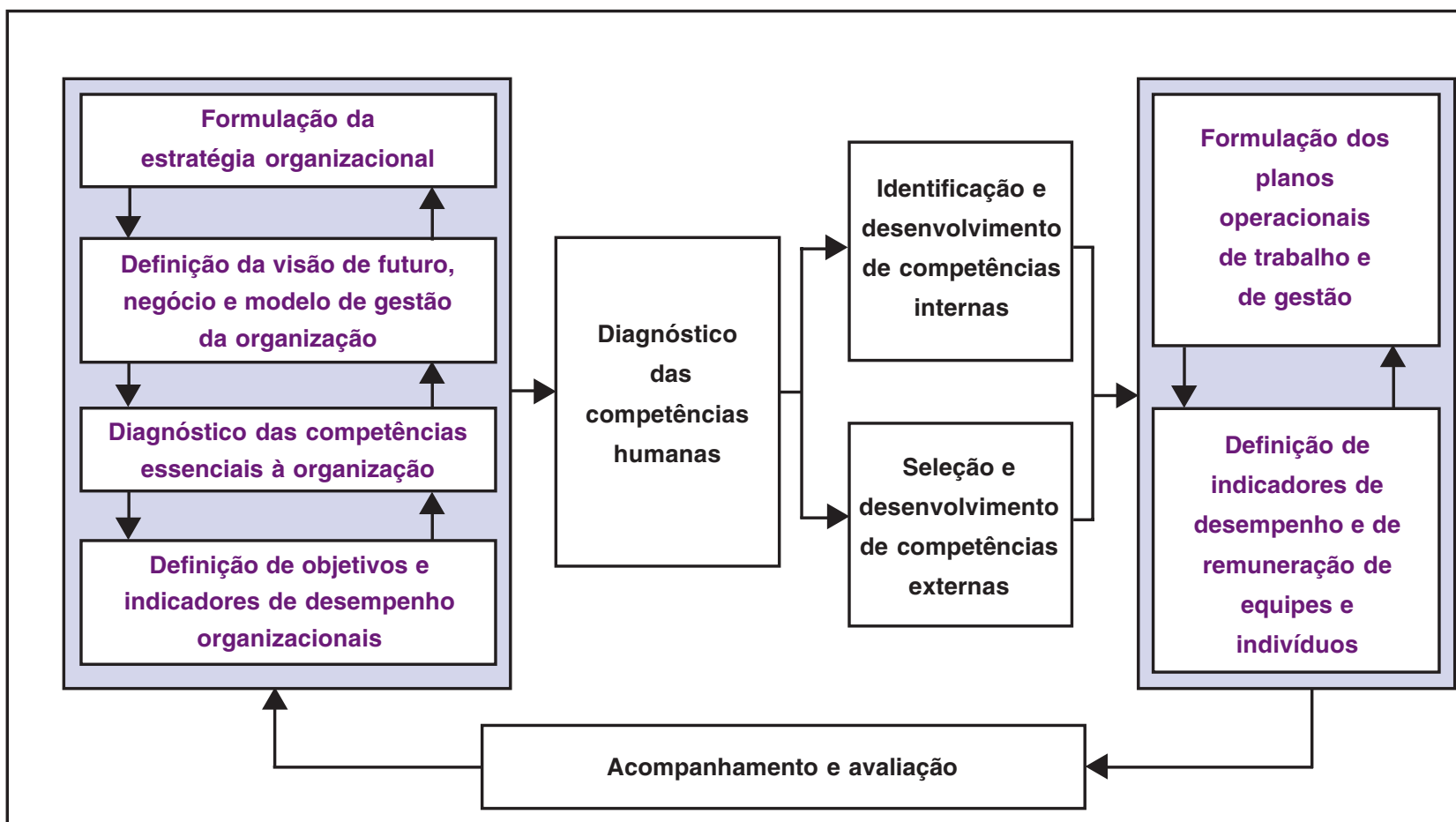

Fonte: Guimarães et al. (2000) (adaptado). 
individual, conforme sugerido por Guimarães et al. (2000), justificando-se, portanto, a reconceituação ou releitura de conceitos aqui proposta (ver Figura 3).

Quando utilizados com a finalidade de objetivação e individualização do trabalho, esses instrumentos apenas aprofundam o controle psicossocial da organização sobre seus empregados, o que pode até ser legítimo do ponto de vista patronal, mas retira a "roupagem moderna" da gestão estratégica de recursos humanos. Nesse caso, estaríamos diante de uma espécie de neofordismo, como o define Legge (1995), ou de novas formas de controle da mãode-obra, sob a perspectiva de uma flexibilidade nas relações de trabalho que submete o empregado a ritmos cada vez mais intensos de trabalho com o objetivo de alcançar níveis crescentes de produtividade.

Para finalizar, é possível inferir que o desafio das organizações está relacionado à utilização de tais instrumentos associados a práticas de aprendizagem coletiva, desenvolvimento de equipes e gestão do conhecimento, dentre outras, que ofereçam múltiplas oportunidades de crescimento profissional e estimulem as pessoas não apenas a desenvolver coletivamente competências mas também a compartilhá-las. Do contrário, esses instrumentos de gestão poderiam até apresentarse com uma roupagem moderna, mas, de fato, não representariam inovações nas práticas de gestão. $\bigcirc$

\section{REFERÊNCIAS BIBLIOGRÁFICAS}

ALURI, R., REICHEL, M. Performance evaluation: a deadly disease? The Journal of Academic Librarianship, v. 20 , n. 3, p. 145-155, July 1994.

ARRÈGLE, J. L. Le savoir et l'approche "resource based": une ressource et une compétence. Revue Française de Gestion, n. 105, p. 84-94, sept./oct. 1995

DURAND, T. Forms of incompetence. In: INTERNATIONAL CONFERENCE ON COMPETENCE-BASED MANAGEMENT, 4. , 1998, Oslo. Proceedings... Oslo : Norwegian School of Management, 1998.

DURAND, T. L'alchimie de la compétence. Revue Française de Gestion, n. 127, p. 84-102, jan./fév. 2000.

DUTRA, J. S., HIPÓLITO, J. M., SILVA, C. M. Gestão de pessoas por competências. In: ENCONTRO NACIONAL DA ASSOCIAÇÃO NACIONAL DOS PROGRAMAS DE PÓS-GRADUAÇÃO EM ADMINISTRAÇÃO, 22., 1998, Foz do Iguaçu. Anais... Foz do Iguaçu : Anpad, 1998.

EDWARDS, M. R., EWEN, A. J. $360^{\circ}$ feedback: the new model for employee assessment \& performance improvement. New York : American Management Association, 1996.

GOODALE, J. G. Improving performance appraisal. Business Quarterly, v. 57, n. 2, p. 65-70, 1992.

GUIMARÃES, T. A. Gestão do desempenho em organizações públicas descentralizadas. In: CONGRESSO INTERNACIONAL DO CLAD, 3., 1998, Madrid. Anais... Madrid : Clad, 1998.

GUIMARÃES, T. A., NADER, R. M., RAMAGEM, S. P. Avaliação de desempenho de pessoal: uma metodologia integrada ao planejamento e avaliação organizacionais. Revista de Administração Pública, v. 32, n. 6, p. 43-61, 1998.

GUIMARÃES, T. A. et al. Forecasting core competencies in R\&D environment. In: INTERNATIONAL CONFERENCE ON MANAGEMENT OF TECHNOLOGY, 9., Feb. 2000, Miami. Proceedings... Miami : International Association for Management of Technology, 2000.
HEENE, A., SANCHEZ, R. Competence-based strategic management. Chichester, England: John Wiley \& Sons, 1997.

HIRATA, H. Os mundos do trabalho: convergência e diversidade num contexto de mudança dos paradigmas produtivos. In: CASALI, A. et al. (Orgs.). Empregabilidade e educação: novos caminhos no mundo do trabalho. São Paulo : Editora da PUC, 1997. p. 23-42.

IENAGA, C. H. Competence-based management: seminário executivo. São Paulo : Dextron Consultoria Empresarial, 1998

ISAMBERT-JAMATI, V. 0 apelo à noção de competência na revista L'Orientation Scolaire et Profissionelle. In: ROPÉ, F., TANGUY, L. (Orgs.). Saberes e competências: o uso de tais noções na escola e na empresa. Campinas: Papirus, 1997. p. 103-133.

LEGGE, K. Human resource management: rhetorics and realities. London : McMillan, 1995.

LUCENA, M. D. S. Avaliação de desempenho: métodos e acompanhamento. São Paulo : McGraw-Hill do Brasil, 1977.

OLIVEIRA-CASTRO, G. A., LIMA, G. B. C., VEIGA, M. R. M. Implantação de um sistema de avaliação de desempenho: métodos e estratégias. Revista de Administração, v. 31 n. 3, p. 38-52, 1996.

PAGÈS, M. et al. O poder das organizações. São Paulo : Atlas, 1993.

PRAHALAD, C. K., HAMEL, G. The core competence of the corporation. Harvard Business Review, v. 68, n. 3, p. 79-91, May/June 1990

RAUB, S. P. A knowledge-based framework of competence development. In: INTERNATIONAL CONFERENCE ON COMPETENCE-BASED MANAGEMENT, 4., 1998, Oslo. Proceedings... Oslo : Norwegian School of Management, 1998.

ROPÉ, F., TANGUY, L. Introdução. In: ROPÉ, F., TANGUY, L. (Orgs.). Saberes e competências: o uso de tais noções na escola e na empresa. Campinas : Papirus, 1997. p. 15-24.
SPARROW, P. R., BOGNANNO, M. Competency requirement forecasting: issues for international selection and assessment. In: MABEY, C., ILES, P. (Orgs.). Managing learning. London : Routledge, 1994. p. 57-69.

SPINK, P. Empregabilidade: comentários a partir do ensaio de Helena Hirata. In: CASALI, A. et al. (Orgs.). Empregabilidade e educação: novos caminhos no mundo do trabalho. São Paulo : Editora da PUC, 1997. p. 51-57.

STEWART, T. A. Capital intelectual: a nova vantagem competitiva das empresas. Rio de Janeiro : Campus, 1998.

TANGUY, L. Competências e integração social na empresa. In: ROPE, F., TANGUY, L. (Orgs.). Saberes e competências: 0 uso de tais noções na escola e na empresa. Campinas : Papirus, 1997. p. 167-200.

TAYLOR, F. W. Princípios de administração científica. São Paulo : Atlas, 1970

TAYLOR, S., BEECHLER, S., NAPIER, N. Toward an integrative model of strategic international human resource management The Academy of Management Review, v. 21, n. 4, p. 959985 , Oct. 1996

TILLES, S. Como avaliar a estratégia das empresas. Rio de Janeiro : COPPEAD/UFRJ, 1997. Mimeo. Tradução de: How to evaluate a corporate strategy, Harvard Business Review.

WRIGHT, R., VAN, W. G., BOUTY, I. Les principes du management des ressources fondées sur le savoir. Revue Française de Gestion, n. 105, p. 70-75, sept./oct. 1995.

ZARIFIAN, P. A gestão da e pela competência. In: SEMINÁRIO EDUCAÇÃO PROFISSIONAL, TRABALHO E COMPETÊNCIAS. Rio de Janeiro : Centro Internacional para a Educação, Trabalho e Transferência de Tecnologia, 1996. Mimeo.

ZARIFIAN, P. Objectif compétence: pour une nouvelle logique. Paris : Editions Liaisons, 1999.

\section{NOTAS}

Os autores agradecem as críticas e sugestões recebidas dos professores Waldyr Viegas e Guillermo Asper, da Universidade de Brasília, e do professor Mozar José de Brito, da Universidade Federal de Lavras.
1. Henri Pestalozzi (1746-1827), pedagogo suíço, idealizou a educação como 0 desenvolvimento natural, espontâneo $e$ harmônico das capacidades humanas que se revelam na tríplice atividade da cabeça, das mãos e do coração (head, hand e heart), isto é, na vida intelectual, técnica e moral do indivíduo. Ver LARROYO, Francisco. História geral da pedagogia. São Paulo : Mestre Jou, 1974.
2. Empregabilidade diz respeito à probabilidade que pode ter um indivíduo à procura de um emprego de encontrá-lo, isto é, refere-se à probabilidade de reinserção no mercado formal de trabalho. Quanto mais qualificado ou competente for 0 indivíduo, maior sua empregabilidade. Ver CASALI, A. et al. (Orgs.). Empregabilidade e educaçãa: novos caminhos no mundo do trabalho. São Paulo : Editora da PUC, 1997. 